\title{
Antidiuretic Effects of Dibutyryl-Cyclic AMP Microinjected into the Hypothalamic Paraventricular Nucleus in a Water-Loaded and Ethanol-Anesthetized Rat
}

\author{
Mayumi MORI, Hiromi TSUSHIMA and Tomohiro MATSUDA \\ Department of Pharmacology, Nagoya City University Medical School. \\ Kawasumi, Mizuho-ku, Nagoya 467. Japan
}

Accepted November 5, 1985

\begin{abstract}
Effects of dibutyryl-cyclic AMP (db-cAMP) and cyclic AMP (cAMP) when microinjected into the hypothalamic paraventricular nucleus ( $P V N$ ) in a water-loaded and ethanol-anesthetized rat on the rate of urine outflow, urine osmotic pressure and other visceral functions were investigated. The microinjection of $\mathrm{db}$-cAMP decreased the rate of urine outflow with concomitant increase in the urine osmotic pressure, but did not change mean blood pressure, heart rate, respiration rate and rectal temperature. The antidiuretic effect of db-CAMP was more potent than the effect of CAMP, the median effective doses (ED50) being approx. $40 \mathrm{nmol}$ for $\mathrm{db}-\mathrm{cAMP}$ and more than $300 \mathrm{nmol}$ for CAMP, respectively. The time-courses for the antidiuretic effects and for the increase in the urine osmotic pressure showed a similar pattern, with the maximal effect at approx. 30 to $40 \mathrm{~min}$ and the duration of approx. one hour or longer. The effect of db-cAMP was potentiated by pretreatment with methylxanthines and inhibited by pretreatment with atropine. A second microinjection of $\mathrm{db}$-cAMP induced a less potent antidiuretic effect than the first microinjection (tachyphylaxis). The results indicated the antidiuretic effects of microinjection of $\mathrm{db}-\mathrm{CAMP}$ and CAMP into the PVN, and a possible mechanism for this was discussed.
\end{abstract}

The paraventricular nucleus (PVN) in the hypothalamus is known to contain magnocellular neurons which synthesize antidiuretic hormone $(A D H)$. The hormone synthesized in the PVN is transported through the axonal tracts to the neurohypophysis. When the neurons are stimulated, the hormone is released from the neurohypophysis into the general circulation and enhances water reabsorption from the distal tubule and collecting duct of the kidney, resulting in an antidiuretic effect (1-4).

The presence of an acethylcholine (ACh) system in the nucleus $(5,6)$ and the finding that iontophoretic application of ACh excites the neurons of the PVN (7) have suggested a role of cholinergic innervation in the nucleus. Microinjection of muscarinic agonists such as oxotremorine and ACh into the nucleus causes potent antidiuretic effects, which are blocked completely by preinjection of a muscarinic antagonist, atropine, indicating that the stimulation of muscarinic receptors induced the antidiuretic effect (8).

On the other hand, histofluorescence of catecholamine-containing varicosities and immunohistochemical localization of nerve terminals containing catecholamine-synthesizing enzymes on the magnocellular neurons in the PVN strongly suggest adrenergic regulation of $A D H$ release (9-12). The $\beta$-adrenoceptor agonist isoproterenol when microinjected into the PVN induces a strong antidiuretic effect, which is stereospecific and blocked completely by $\beta$ adrenoceptor antagonists. The antidiuretic effect induced by the $\beta$-adrenoceptor agonist is inhibited partially by the muscarinic antagonist (13), suggesting a portion of the 
effect may be due to the release of $\mathrm{ACh}$ from presynaptic area. Since adenosine- $3^{\prime}, 5^{\prime}$ cyclic monophosphate (CAMP) as a second messenger of $\beta$-adrenoceptor stimulation is known to enhance the release of $\mathrm{ACh}$ in the neuromuscular junction (14), the intestine (15, 16) and the brain (17-19), we tried to test the effects of microinjection of CAMP and its analog into the PVN in the present study by determining the following: antidiuretic effects, inhibitory effects by the muscarinic antagonist, and effects on other visceral functions which might affect the urine outflow. Urine osmotic pressure was also measured in order to know whether the antidiuretic effect was due to enhanced reabsorption of water by antidiuretic hormone.

\section{Materia!s and Methods}

Animals and drugs: Male Wistar rats, weighing 280-320 g, were used. Adenosine$3^{\prime}, 5^{\prime}$-cyclic monophosphate (CAMP) sodium salt and $\mathrm{N}^{6},-\mathrm{O}^{\prime \prime}$-dibutyryl-adenosine- $3^{\prime}, 5^{\prime}$ cyclic monophosphate (db-cAMP) sodium salt (Sigma Chemical Co., St. Louis, MO), atropine sulfate (Iwaki Co., Tokyo), phenoxybenzamine hydrochloride (Nakarai Chemicals, Kyoto), theophylline (Wako Pure Chemical Industries, Ltd., Osaka), and 3-isobutyl-1methylxanthine (IBMX, Sigma Chemical Co., St. Louis, MO) were purchased. The other chemicals used were the analytical grade available.

Measurement of urine outflow and urine osmotic pressure: Urine outflow was measured by the method of Dicker, with some modifications $(8,20)$. The rats were starved overnight for approx. $17 \mathrm{hr}$, having free access to water. The animals were loaded orally through a catheter with a volume of water equivalent to $5 \%$ of the body weight and then the same volume of $12 \%$ ethanol. The cannulae were inserted into the trachea, bladder, and external jugular vein, respectively. The rat was then fixed in a stereotaxic instrument for rats (Takahashi Co., Tokyo). The number of drops of urine outflow from the cannula inserted into the bladder was counted using a photoelectric drop counter (DCT 102, Unique Medical Inc. Tokyo) and recorded as single pulses. Three percent ethanol in Locke solution was infused at a constant rate of $0.10 \mathrm{ml} / \mathrm{min}$ through the cannula inserted into the jugular vein in order to maintain a constant level of anesthesia and a constant rate of urine outflow. Osmotic pressure of urine was measured by the freezing point depression method (The Fiske Osmometer, Fiske Associates, Inc., Uxbridge, MA).

Microinjection of drugs: A stainless cannula (outer diameter: $200 \mu \mathrm{m}$ ) was inserted stereotaxically and unilaterally into the PVN according to the atlas of König and Klippel (21). Dibutyryl-CAMP and CAMP were dissolved in saline ( $\mathrm{pH}$ approx. 7), IBMX was dissolved in $3 \%$ ethanol in saline $(\mathrm{pH}$ approx. 7), and other compounds in an artificia! cerebrospinal fluid (CSF: $128 \mathrm{mM}$ $\mathrm{NaCl}, 3.0 \mathrm{mM} \mathrm{KCl}, 1.2 \mathrm{mM} \mathrm{CaCl}_{2}, 0.8 \mathrm{mM}$ $\mathrm{MgCl}_{2}, 0.65 \mathrm{mM} \mathrm{NaH}_{2} \mathrm{PO}_{4}$ and $4.8 \mathrm{mM}$ $\mathrm{NaHCO}_{3}, \mathrm{pH} 7.4$ ). Drugs were injected using a microsyringe in a volume of $1 \mu$ l through the cannula. Then $2 \mu$ ! of the artificial CSF was injected at a rate of approx. $0.3 \mu / \mathrm{min}$. The microinjection was performed when the urine outflow reached a constant rate of 0.05-0.16 $\mathrm{ml} / \mathrm{min}$ within one hour after the animal was fixed in the stereotaxic instrument. Effects of drugs on urine outflow during every $10 \mathrm{~min}$ were expressed as a percent of the initial constant outflow.

In the experiment to test the effect of pretreatment with atropine or timolol, microinjection of $\mathrm{db}$-cAMP was carried out at 30 to $60 \mathrm{~min}$ after premicroinjection of atropine when the urine outflow had recovered to the initial level or at 20 to $30 \mathrm{~min}$ after premicroinjection of timolol. In the experiments to see the effects of pretreatment with phenoxybenzamine and phosphodiesterase inhibitors. the time interval between the premicroinjection and microinjection of CAMP or $\mathrm{db}$-cAMP was $20 \mathrm{~min}$. The effect of preinjection of a drug was estimated as the change in antidiuretic effect caused by the injection of db-CAMP with and without the pretreatment in separat? rats because of tachyphylaxis in the antidiuresis induced by the dibutyryl analog.

Identification of the sites of inserted cannula: The position of the tip of the cannula inserted stereotaxically into the PVN was confirmed by the following methods: 1) 
functionally, by the appearance of an antidiuretic effect by microinjecting a depolarizing dose $(400 \mathrm{nmol})$ of $\mathrm{KCl}$ through the cannula and 2) histochemically, by the localization of the tip of the cannula in a group of magnaocellular cells in the PVN positively stained by the method of Gomori (22).

Measurement of blood pressure, heart rate, respiration rate and rectal temperature: Mean blood pressure and heart rate were measured through a cannula inserted into the carotid artery with a pressure transducer (MPU-0.5-290-O-III, Nihon Kohden Kogyo. Co., Tokyo) and by an electrocardiograph (FD-14, Fukuda, Tokyo), respectively. Respiration rate was measured by a thermister probe (SR-115S, Nihon Kohden Kogyo, Co.) inserted into a tracheal catheter. These three indices were recorded simultaneously on a recticorder (RJG-3004-2, Nihon Kohden Kogyo, Co.). Rectal temperature was monitored by a thermister probe (MGA III219. Nihon Kohden Kogyo, Co.) inserted into the rectum.

Statistical analysis: Significance of differences between mean values was determined by Student's $t$-test. The differences were considered significant at $\mathrm{P}<0.05$.

\section{Resultrs}

Effects of microinjection of db-cAMP and cAMP on urine outflow: Figure 1 a shows the effects of various doses of db-cAMP on urine outfiow as a function of time after their microinjections into the PVN. DibutyrylCAMP caused the antidiuretic effect in a dose-dependent and time-dependent manner. The urine outflow decreased within $20 \mathrm{~min}$, with a minimal outflow at 30 to $40 \mathrm{~min}$, and recovered to the initial level at approx. $1.5 \mathrm{hr}$ after microinjection of 50 and $100 \mathrm{nmol}$ of $\mathrm{db}$-cAMP. Vehicle alone microinjected into the nucleus did not change the urine outflow. As shown in Fig. 1b, the antidiuretic effect of microinjection of CAMP was much less than that of $\mathrm{db}$-cAMP.

Dose-effect curves for db-cAMP and cAMP: Figure 2 demonstrates the doseeffect curves for the antidiuretic effect induced by db-cAMP and CAMP microinjected into the PVN. The approx. median effective doses (ED50) were estimated to be $40 \mathrm{nmol}$ for $\mathrm{db}$-cAMP and more than 300 nmol for CAMP.

Potentiation by pretreatment with phosphodiesterase inhibitors and inhibition by pretreatment with muscarinic antagonist: As illustrated in Fig. 3a, a premicroinjection of $50 \mathrm{nmol}$ theophylline potentiated the antidiuretic effect of microinjection of $50 \mathrm{nmol}$ $\mathrm{db}$-cAMP, but was not able to enhance the effect of microinjection of $100 \mathrm{nmol}$ cAMP (Fig. 3b). A premicroinjection of $10 \mathrm{nmol}$ IBMX potentiated the effect of CAMP (Fig. $3 \mathrm{~b})$ and tended to enhance the antidiuretic

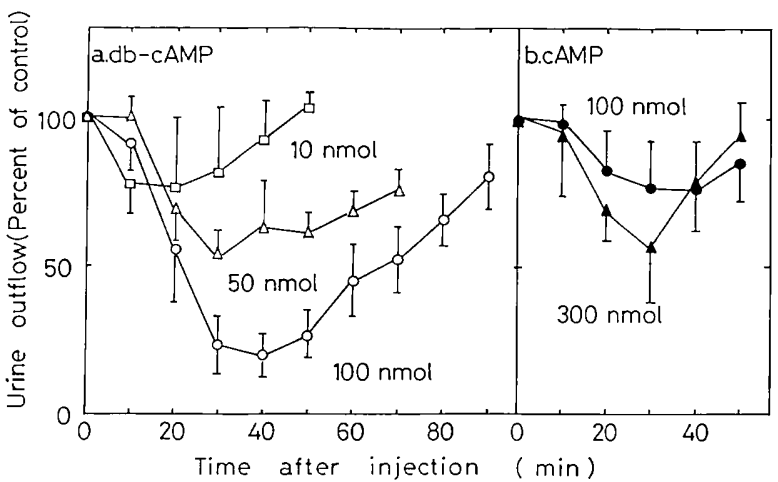

Fig. 1. Time-courses for antidiuresis by microinjection of cyclic nucleotides ( $a$ : db-cAMP: b: cAMP) into the PVN. Abscissa indicates time in min after microinjection of $1 \mu 1$ of drug solution, and ordinate shows urine outflow presented as percent of the initial urine outflow $(a, 0.107 \pm 0.015 ; b, 0.092 \pm 0.016$ $\mathrm{ml} / \mathrm{min})$. Symbols which represent the urine outflow during the preceding $10 \mathrm{~min}$ period are means \pm S.E. from 4-6 experiments. 
effect of db-cAMP (Fig. 3a).

As shown in Fig. 4, the antidiuretic effect of $100 \mathrm{nmol} \mathrm{db}$-cAM!P was completely blocked by premicroinjection of $300 \mathrm{nmol}$ atropine, a muscarinic antagonist, which inhibits completely the antidiuretic effect of ACh (8). The antidiuretic effect of $d b$-cAMP was not altered by premicroinjection of 80

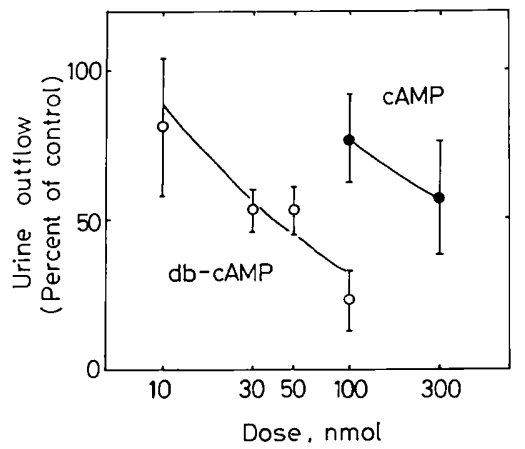

Fig. 2. Dose-effect curves for antidiuretic effects of microinjection of $\mathrm{db}-\mathrm{cAMP}$ and $\mathrm{cAMP}$ into the PVN. Abscissa indicates the dose of cyclic nucleotides microinjected in $1 \mu \mathrm{l}$ of drug solution, and ordinate shows the minimal urine outflow during the preceding $10 \mathrm{~min}$ at $30 \mathrm{~min}$ or $40 \mathrm{~min}$ after microinjection presented as percentage of the initial urine outflow (for db-cAMP: 0.107 \pm 0.015 ; CAMP: $0.092 \pm 0.016 \mathrm{ml} / \mathrm{min})$. Symbols are means \pm S.E. from 4-6 experiments. nmol phenoxybenzamine, an $\alpha$-adrenoceptor antagonist, which blocked the antidiuretic effect of microinjection of $10 \mathrm{nmol}$ norepinephrine (13). Timolol at $100 \mathrm{nmol}$ was not

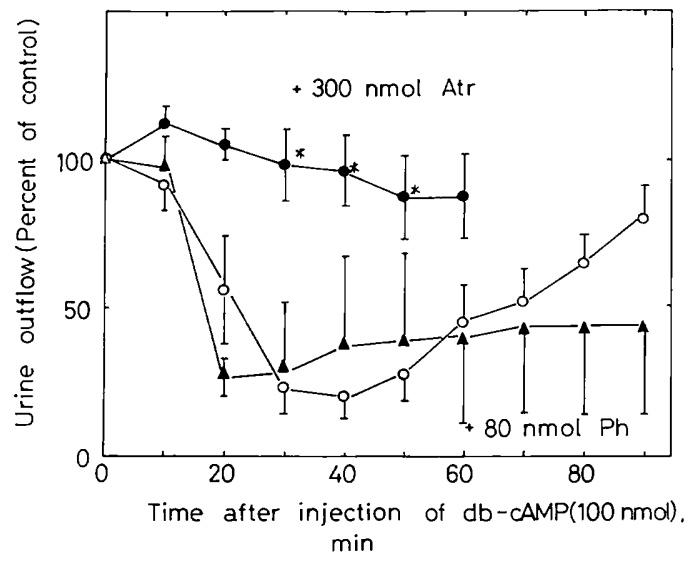

Fig. 4. Effects of pretreatment with atropine and phenoxybenzamine on antidiuresis induced by microinjection of $100 \mathrm{nmol} \mathrm{db}-\mathrm{cAMP}$ into the PVN. $O$ : control, microinjection of db-cAMP alone; pretreatment with microinjection of atropine (300 $\mathrm{nmol}$ ) at 30-60 min before the injection of $\mathrm{db}$-cAMP:

$\boldsymbol{\Delta}$ : pretreatment with microinjection of phenoxybenzamine $(80 \mathrm{nmol})$ at $20 \mathrm{~min}$ before the injection of db-cAMP. Abscissa and ordinate are as in Fig. 3. The initial urine outflow was $0.112 \pm 0.023 \mathrm{ml} / \mathrm{min}$. Symbols are means \pm S.E. from $3-4$ experiments. Significance was as in Fig. $3:{ }^{*} P<0.05$.

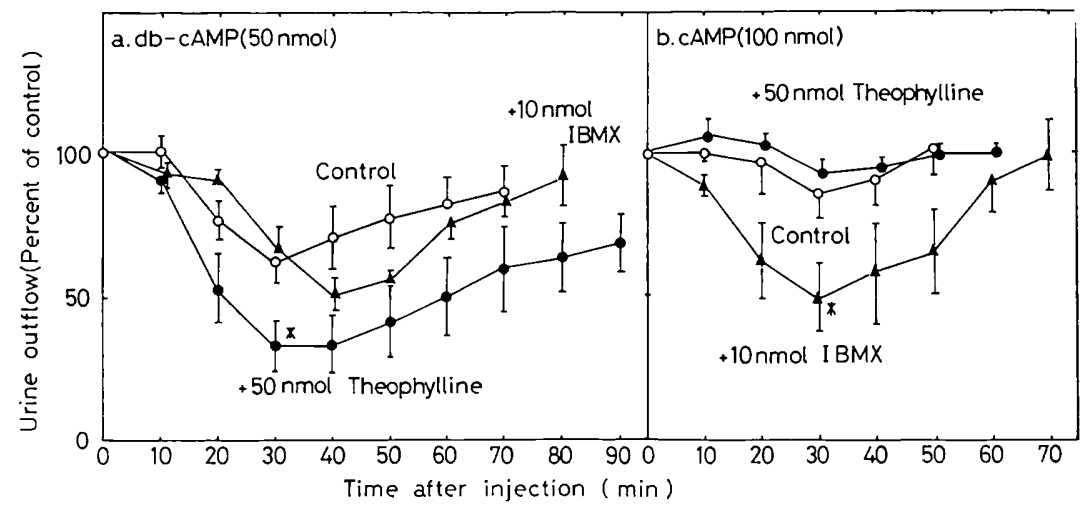

Fig. 3. Effects of pretreatment with theophylline and IBMX on antidiuresis induced by microinjection of $\mathrm{db}$-cAMP and CAMP into the PVN. $\mathrm{a}$ : db-CAMP $(50 \mathrm{nmol})$, b: cAMP $(100 \mathrm{nmol})$. Premicroinjection of : theophylline $(50 \mathrm{nmol})$ and $\mathbf{A}$ : IBMX $(10 \mathrm{nmol})$ at $20 \mathrm{~min}$ before the injection of $\mathrm{db}-\mathrm{CAMP}$ or CAMP. Abscissa indicates time in min after injection, and ordinate shows urine outflow presented as percent of the initial urine outflow (a, $0.108 \pm 0.012 ; b, 0.116 \pm 0.015 \mathrm{ml} / \mathrm{min}$ ). Symbols are means \pm S.E. from 4-6 experiments. " $P<0.05$ : Significance compared with the effect of injection of $\mathrm{db}-\mathrm{cAMP}$ or cAMP alorie at the same time point. 
significantly able to inhibit the effect of db-cAMP.

Tachyphylaxis in the antidiuretic effect by microinjection of $\mathrm{db}$-cAMP: The antidiuretic effect induced by the second microinjection of $100 \mathrm{nmol} \mathrm{db}$-cAMP into the PVN was much less than the effect by the first injection (Fig. 5), while antidiuretic effects caused by the second microinjection of $\mathrm{KCl}$, cholinergic agonists, and adrenoceptor agonists are approx. equal to the effects by the first microiniection $(8,13)$.

Effect of microinjection of db-cAMP on urine osmotic pressure: Figure 6 shows the effects of microinjection of $d b$-CAMP into the $P V N$ on urine osmotic pressure as a function of time after microinjection, compared with the effects on urine outflow. After microinjection of $100 \mathrm{nmol} \mathrm{db}$-cAMP, the urine osmotic pressure appeared to increase at

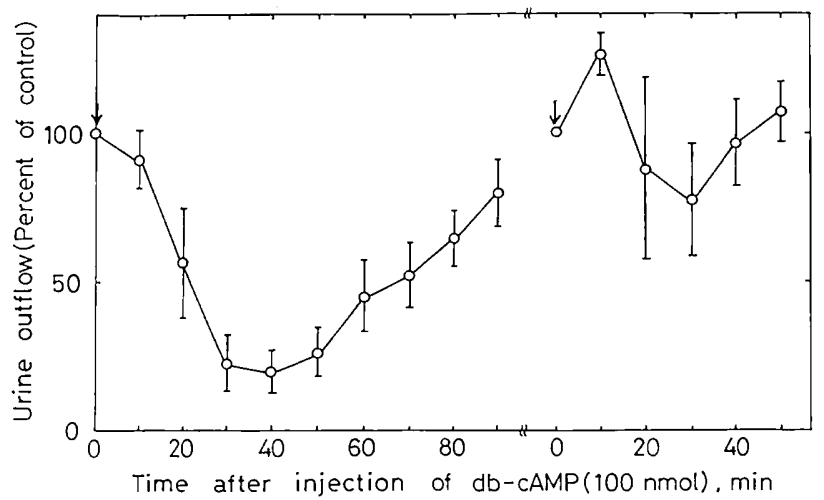

Fig. 5. Antidiuretic effects induced by repeated microinjection of db-cAMP (100 nmol) into the PVN. Drug was injected at the time indicated by the arrows. The time interval between the two arrows was approx. two hours. Abscissa and ordinate are as in Fig. 3. The initial urine outflow was $0.102 \pm 0.023$ $\mathrm{ml} / \mathrm{min}$ at the time of the first injection and $0.081 \pm 0.017 \mathrm{ml} / \mathrm{min}$ at the time of the second injection. Symbols are means \pm S.E. from $4-5$ experiments.

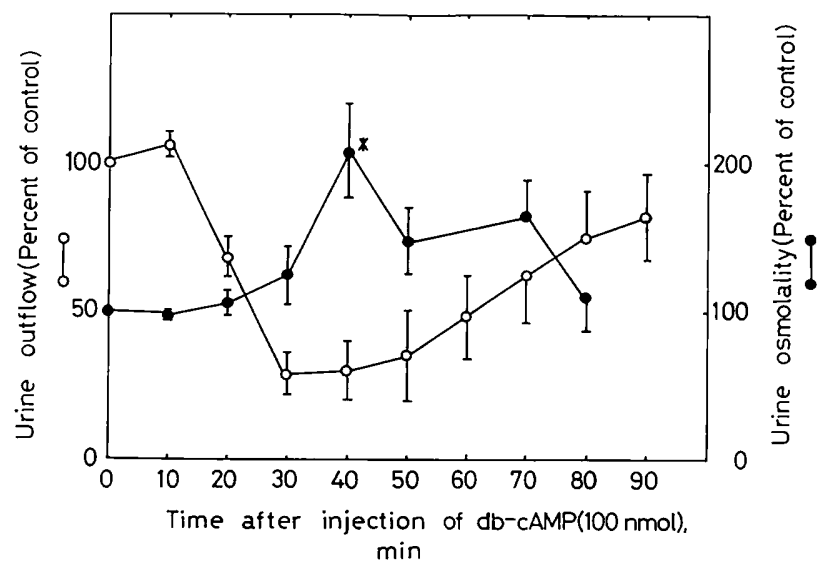

Fig. 6. Time-courses for change in urine osmolality after microinjection of db-cAMP into the PVN. O: urine outflow, : urine osmolality. Abscissa and the left ordinate are as in Fig. 3 . The right ordinate shows osmolality of the urine outflow during the preceding $10 \mathrm{~min}$. The initial urine outflow was $0.137 \pm 0.018 \mathrm{ml} / \mathrm{min}$. Urine osmolality presented as percent of the initial urine osmotic pressure $(265 \pm 18.9 \mathrm{mOsm})$. Symbols are means \pm S.E. from 4 experiments. Significance was as in Fig. 3 : ${ }^{*} \mathrm{P}<0.05$. 
approx. $20 \mathrm{~min}$, with a maximal osmotic pressure of approx. $200 \%$ of the initial control level at $40 \mathrm{~min}$, and recovered to the initial level at approx. $1.5 \mathrm{hr}$. The pattern of time-course curves for urine outflow and for urine osmotic pressure showed an approx. mirror image with minor differences in their configurations.

Effect of microinjection of db-cAMP into the PVN on visceral functions: Some visceral indices which might be expected to be responsive to the microinjection of $d b-C A M P$ into the PVN and which might affect the urine outflow were monitored during the experiments. At 20 and $30 \mathrm{~min}$ after microinjection of $300 \mathrm{nmol} \mathrm{db}$-cAMP, when it induced a marked decrease in the urine outflow, there were no changes in mean blood pressure, heart rate, respiration rate and rectal temperature. Heart rate increased by approx. $10 \%$ at $60 \mathrm{~min}$. when the urine outflow was recovered to approx. $60 \%$ of the initial control outflow.

\section{Discussion}

This is the first paper that demonstrated antidiuretic effects of CAMP and the dibutyryl analog microinjected into the PVN which contains magnocellular neurons synthesizing and releasing antidiuretic hormone, vasopressin. The dibutyryl analog induced more potent antidiuresis than CAMP in a dosedependent and time-dependent manner, the median effective doses (ED50) for db-cAMP being approx. $40 \mathrm{nmol}$ versus more than $300 \mathrm{nmol}$ for CAMP. The time-courses of the effects were relatively slow, with a minimal urine outflow at approx. 30 to $40 \mathrm{~min}$ and the duration of approx. $1.5 \mathrm{hr}$ after microinjection. suggesting that the effects are hormonal rather than through neuronal pathways as found in the case of antidiuretic effects induced by microinjection of cholinergic and adrenoceptor agonists $(8,13)$. The antidiuretic effect of $\mathrm{db}$-cAMP closely correlated with an increase in urine osmotic pressure, indicating that reabsorption of water was enhanced during the antidiuresis.

Since the ED50 value of $\mathrm{KCl}$ for depolarizing the neurons of the PVN was $320 \pm 78 \mathrm{nmol}$ (8), db-cAMP whose ED50 was approx. $40 \mathrm{nmol}$ was approx. eight times more potent than $\mathrm{KCl}$. The median effective concentration for db-cAMP can be roughly estimated to be approx. $4 \mathrm{mM}$, a little higher concentration than the effective concentration usually used (18), provided that central neurons are depolarized by $\mathrm{KCl}$ at approx. $30 \mathrm{mM}$ concentration. As rats were loaded with water and ethanol in order to keep the urine outflow constant and at a measurable flow rate in the present experiments, the true effective concentration for $\mathrm{db}$-cAMP in unanesthetized rats without water- and ethanol-loading could be lower than the value estimated above.

The stronger potency to induce the antidiuretic effect of $d b-c A M P$ which is more permeable through the plasma membrane into the intracellular cytoplasm (23) than that of CAMP and the potentiation of their effects by pretreatment with the inhibitors of phosphodiesterase suggest that their effects may be related to an increased intraceliular level of CAMP. However, it remains to be elucidated why theophylline and IBMX could not significantly potentiate the effects of CAMP and $d b$-cAMP, respectively. The results might reflect differences of the two methylxanthines in the inhibitory effect of phosphodiesterase $(24,25)$ or in effects other than the enzyme inhibition.

Premicroinjection of a muscarinic antagonist, atropine, blocked completely the antidiuretic effect of db-cAMP, which suggests that the effect of db-cAMP was mediated through muscarinic receptor. One possible explanation for this observation is that $\mathrm{db}$-cAMP may release a muscarinic substance, probably $\mathrm{ACh}$ from presynaptic cholinergic terminals on the neurons in the nucleus $(5,6)$ as has been demonstrated in the brain (17-19), neuromuscular junction (14), and small intestine $(15,16)$. However, our previous results that antidiuretic effects induced by norepinephrine and isoproterenol were inhibited only partially by pretreatment with atropine (13) suggest that the presynaptic effect of the catecholamines mediated through CAMP if present may be a part of the antidiuretic effects. Tachyphylaxis in the effect of $d b$-cAMP could be due to the depletion of a relatively small pool of $\mathrm{ACh}$ in the presynaptic area as tachyphylaxis found in the indirect effects of ephedrine and 
tyramine which release norepinephrine from the presynaptic terminals (26)

During antidiuresis induced by microinjection of db-cAMP $(300 \mathrm{nmol})$, no significant changes were observed in various visceral functions such as mean blood pressure, respiration rate and rectal temperature which might affect the urine outflow. with a slight increase in heart rate which was not affected at the time of the maximal antidiuretic effect, at 30 to $40 \mathrm{~min}$ after microinjection. Therefore, the antidiuretic effect of db-cAMP is not likely due to the changes in these visceral functions.

In summary, the present data indicate for the first time antidiuretic effects of $d b$-cAMP and CAMP when microinjected into the PVN which contains neurons synthesizing and releasing antidiuretic hormone. A possible mechanism of the effect of $\mathrm{db}$-CAMP may be due to a release of $\mathrm{ACh}$, which stimulates muscarinic receptors in the PVN (8).

\section{References}

1 Reichlin, S.: Neuroendocrinology. In Textbook of Endocrinology, Edited by Williams, R. H., p. 589645. W. B. Saunders Co., Philadelphia (1981)

2 Schrier, R.W. and Leaf, A.: Effects of hormones on water, sodium, chloride, and potassium metabolism. In Textbook of Endocrinology, Edited by Williams, R. H., p. 1032-1046, W. B. Saunders Co., Philadelphia (1981)

3 Zimmerman, E.A.: Oxytocin, vasopressin, and neurophysins. In Brain Peptides, Edited by Krieger, D.T., Brownstein, M.J. and Martin, J.B., p. 597-611, John Wiley \& Sons, New York (1983)

4 Reid, I.A.: Salt and water regulation. In Brain Peptides, Edited by Krieger, D.T., Brownstein, M.J. and Martin, J.B., p. 333-347, John Wiley \& Sons, New York (1983)

5 Feldberg, W. and Vogt, M.: Acetylcholine synthesis in different regions of the central nervous system. J. Physiol. (Lond.) 107, 372381 (1948)

6 Abrahams, V.C., Koelle, G.B. and Smart, P.: Histochemical demonstration of cholinesterases in the hypothalamus of the dog. J. Physiol. (Lond.) 139, 137-144 (1957)

7 Cross, B.A., Moss, R.L. and Urban, I: Effect of iontophoretic application of acetylcholine and noradrenaline to antidromically identified paraventricular neurones. J. Physiol. (Lond.) 214, 28P-30P (1971)
8 Mori, M., Tsushima, H. and Matsuda, T.: Antidiuretic effects of oxotremorine microinjected into the hypothalamic supraoptic and paraventricular nuclei in a water-loaded and ethanolanesthetized rat. Japan. J. Pharmacol. 35, 2736 (1984)

9 McNeill, T.H. and Sladek, J.R., Jr.: Simultaneous monoamine histofluorescence and neuropeptide immunocytochemistry. II. Correlative distribution of catecholamine varicosities and magnocellular neurosecretory neurons in rat supraoptic and paraventricular nuclei. J. Comp. Neurol. 193, 1023-1033 (1980)

10 Swanson, L.W., Sawchenko, P.E., Bérod, A., Hartman, B.K., Helle, K.B. and Vanorden, D.E.: An immunohistochemical study of the organization of catecholaminergic cells and terminal fields in the paraveritricular and supraoptic nuclei of the hypothalamus. J. Comp. Neurol. 196, 271-285 (1981)

11 Sawchenko, P.E. and Swanson, L.W.: Central noradrenergic pathways for the integration of hypothalamic neuroendocrine and autonomic responses. Science 214, 685-687 (1981)

12 Swanson, L.W. and Sawchenko, P.E.: Hypothalamic integration: Organization of the paraventricular and supraoptic nuclei. Annu. Rev. Neurosci. 6, 269-324 (1983)

13 Tsushima, H., Mori, M. and Matsuda, T.: Antidiuretic effects of alpha- and betaadrenoceptor agonists microinjected into the hypothalamic paraventricular nucleus in a water-loaded and ethanol-anesthetized rat. Japan. J. Pharmacol. 40, 319-328 (1986)

14 Miyamoto, M.D. and Breckenridge, B.McL.: A cyclic adenosine monophosphate link in the catecholamine enhancement of transmitter release at the neuromuscular junction. J. Gen. Physiol. 63, 609-624 (1974)

15 Alberts, P. and Stjärne, L.: Secretion of ${ }^{3} \mathrm{H}$ acetylcholine from guinea-pig ileum myenteric plexus is enhanced by $8-\mathrm{Br}$ adenosine $3^{\prime}, 5^{\prime}$ cyclic monophosphate but not changed by $8-\mathrm{Br}$ guanosine $3^{\prime}, 5^{\prime}$-cyclic monophosphate. Acta Physiol. Scand. 115, 269-272 (1982)

16 Reese, J.H. and Cooper, J.R.: Stimulation of acetylcholine release from guinea-pig ileal synaptosomes by cyclic nucleotides and forskolin. Biochem. Pharmacol. 33, 3007-3011 (1984)

17 Matsuda, T., Yonehara, N., Noguchi, Y., Hata, F., Kuo, C.H., Katsuki, S. and Yoshida, H.: Factors which may regulate synthesis and release of acetylcholine in the nerve terminals of the rat brain. In Neurobiology of Chemical Transmission, 
Edited by Otsuka, M., and Hall, Z.W., p. 77-89, John Wiley \& Sons, New York (1979)

18 Katsuki, S., Matsuda, T., Hata, F. and Yoshida, $\mathrm{H}$. : Increase in $\mathrm{ACh}$ release from the rat brain cortex slices by $3^{\prime}, 5^{\prime}$-cyclic adenosine monophosphate. Japan. J. Pharmacol. 27, 173-175 (1977)

19 Sciorelli, G., Poloni, M. and Rindi, G.: Evidence of cholinergic mediation of ingestive responses elicited by dibutyryl-adenosine- $3^{\prime}, 5^{\prime}$-monophosphate in rat hypothalamus. Brain Res. 48, 427-431 (1972)

20 Dicker, S.E.: A method for the assay of very small amounts of antidiuretic activity with a note on the antidiuretic titre of rat's blood. J. Physiol. (Lond.) 122, 149-157 (1953)

21 König, J.F.R. and Klippel, R.A.: The Rat Brain, A Stereotaxic Atlas of the Forebrain and Lower Parts of the Brain Stem. Williams and Wilkins Co., Baltimore (1963)

22 Bergmann, W.: Über die neurosekretrische Verknüpfung von Hypothalamus und Neuro- hypophyse. Z. Zellforsch. 34, 610-634 (1949)

23 Posternak, Th., Sutherland. E.W. and Henion, W.F.: Derivatives of cyclic $3^{\prime}, 5^{\prime}$-adenosine monophosphate. Biochim. Biophys. Acta 65, 558-560 (1962)

24 Dunlop, M., Larkins, R.G. and Court, J.M.: Methylxanthine effects on cyclic adenosine $3^{\prime}, 5^{\prime}$ monophosphate phosphodiesterase activity in preparations of neonatal rat cerebellum: Modification by trifluoperazine. Biochem. Biophys. Res. Commun. 98, 850-857 (1981)

25 Wells, J.N., Wu, Y.J., Baird, C.E. and Hardman, J.G.: Phosphodiesterases from porcine coronary arteries: Inhibition of separated forms by xanthines, papaverine, and cyclic nucleotides. Mol. Pharmacol. 11, 775-783 (1975)

26 Mayer, S.E.: Drugs acting at synaptic and neuroeffector junctional sites. In The Pharmacological Basis of Therapeutics, Sixth Edition, Edited by Gilman, A.G., Goodman, L.S. and Gilman, A., p. 56-90, MacMillan Publishing Co., Inc. New York (1980) 